\title{
Initial Segmentation Patterns of Microspores and Pollen Viability in Soybean Cultured Anthers: Indication of Chromosome Doubling
}

\author{
Milena Barcelos Cardoso ${ }^{1}$, Eliane Kaltchuk-Santos ${ }^{1}$, Elsa Cristina de Mundstock $^{2}$ and \\ Maria Helena Bodanese-Zanettini ${ }^{1^{*}}$ \\ ${ }^{1}$ Departamento de Genética; Universidade Federal do Rio Grande do Sul; C. P. 15053; 91501-970; Porto Alegre - RS - \\ Brazil. ${ }^{2}$ Departamento de Estatística; Universidade Federal do Rio Grande do Sul; Porto Alegre - RS - Brazil
}

\begin{abstract}
Anthers obtained from flowers buds of soybean cultivar IAS -5 were cultured in two basal culture media (B5 and B5 long). Cytological examinations of the in vitro anthers were performed during the first 20 days of culture to assay the viability (by propionic-carmine and fluorescein diacetate tests) and the stage of development of pollen grains. The frequencies of viable pollen grains varied significantly between bud sizes on the propionic-carmine analysis. The basal culture media and bud size had no clear effect on the frequencies of binucleate symmetrical and multinucleate pollen grains. Chromosome counts of metaphasic microspores throughout the culture period showed microspores with higher ploidy level in addition to normal chromosome number $(n=20)$.
\end{abstract}

Key words: Glycine max, FDA, binucleate pollen grains, multinucleate pollen grains, spontaneous diploidization

\section{INTRODUCTION}

In vitro anther or microspore culture provides a useful method for haploid plant production, which can be used to develop homozygous pure lines for crop-breeding programs. Homozygous seeds and plants are essentially ideal material for genetics, molecular biology, biotechnology, and for plant breeding. Although the production of haploid plants of a number of crops is now a routine practice, progress is still slow in some species because of the low frequency of plant regeneration (Atanassov et al., 1995).

In spite of many efforts, there seems to be no reproducible and efficient system available for the production of soybean androgenic plantlets yet. Tang et al. (1973) were the first to obtain calli from soybean anther culture. Yin et al. (1980, 1982) obtained sporadic haploid plantlets from Chinese soybean cultivars. In almost all the subsequent studies on haploid induction through anther culture, only calli or few embryos, which died at a very early stage of development, were obtained (Hu et al., 1996).

Being aware of the serious lack of basic information, our laboratory has set forth projects to gather cytological and histological data related to anther culture (Kaltchuk-Santos et al., 1993, 1997; Lauxen et al., 2003), with the goal of identifying factors that are important for the stimulation of soybean androgenesis and establishing a protocol that would permit the production of dihaploid plants.

\footnotetext{
Author for correspondence
} 
Many factors have been recognized as affecting the response of cultured anthers, including genotype, physiological state and growth conditions of donor plants, stage of pollen development, pretreatment of anthers and composition of the culture medium (Smýkal, 2000). The importance of the basal medium composition for anther culture was recognized quite early (Maheshwary et al., 1982). There is a continually expanding list of media suitable for a range of species, but most media are specific for a few or even only one genotype. Therefore, no single anther culture media can be recommended for general use (Atanassov et al., 1995). Yin et al. (1982) and Jian et al. (1986) tested several basal media for soybean anther culture. These studies determined that B5 medium (Gamborg et al., 1968) provided the highest frequency of callus induction. Later studies conducted by Zhuang et al. (1991) and by our research team (KaltchukSantos et al. 1997) used B5 salts enriched with 16 organic compounds (B5 long medium). Considering that B5 long is an expensive medium, which demands a tedious preparation, it is very important to test the effectiveness of this medium and compare it to B5.

The stage of pollen development at the time of culture initiation markedly affects androgenesis as well. Pollen grains can be switched towards the sporophytic pathway within only a narrow period. For most species, the period around the first haploid mitosis (late uninucleate or early binucleate pollen grains) has been shown to be the critical stage for pollen susceptibility to androgenic induction (Reynolds, 1997). To improve the selection of soybean anthers for culture, Ivers et al. (1974) and Yin et al. (1982) correlated bud stages with microspore differentiation for American cultivar 'Hark' and Chinese cultivars, respectively.

We carried out a study in our laboratory to establish the association between flower bud sizes and the corresponding microspore developmental stages for soybean cultivars used in Brazil. Data indicated that for a given bud size, the microspores of different cultivars were at different stages (Lauxen et al., 2003). Specifically for cv. IAS-5, uninucleate microspores were found in buds with $2.5-3.5 \mathrm{~mm}$ in size. This paper reports the results of new attempts towards the improvement of androgenesis in soybean by testing different induction basal media and flower bud sizes. The study included the analysis of pollen viability, pollen developmental stages and the occurrence of spontaneous chromosome doubling.

\section{MATERIAL AND METHODS}

The North American-adapted cultivar IAS-5, commonly used in genetic improvement programs and for commercial growing in the Brazilian state of Rio Grande do Sul, was used in this study. Plants were grown in field conditions. The harvested inflorescences were stored at low temperature $\left(4^{\circ} \mathrm{C}\right.$ to $\left.7^{\circ} \mathrm{C}\right)$ for 1 or 2 days. Flower buds were sterilized in $70 \%$ ethanol for $15 \mathrm{~s}$ followed by immersion in a $2 \%$ sodium hypochlorite solution for $12 \mathrm{~min}$ and rinsed three times with sterilized distilled water. Two flower bud sizes $(2.5-2.9$ and $3.0-3.5 \mathrm{~mm})$ were aseptically plated onto two different culture media: B5 and B5 long (Carolina Biological Supply Co., Burlington, NC, USA). Both media were supplemented with Yeung's amino acids (Yeung and Sussex, 1979), 2mg. $\mathrm{L}^{-1}$ 2,4-D (dichlorophenoxy acetic acid), 0,5 mg. $\mathrm{L}^{-1} \mathrm{BA}$ (benzyladenine), 9\% sucrose and gelled with $0.3 \%$ Phytagel (Sigma Chemical Co.). On average, 1,200 anthers (100 per Petri dish) were cultured in each treatment, totaling 4,800 anthers. Petri dishes (90 $\mathrm{mm}$ in diameter) were incubated at $25^{\circ} \mathrm{C}$ under a 16 hour photoperiod. Ten anthers were randomly collected from each Petri dish at $0,5,10,15$, and 20 days of culture for cytological analysis. To determine pollen viability, 5 anthers were used in vivo for FDA (Fluorescein diacetate) test (HeslopHarrison and Heslop-Harrison, 1970). Five anthers were fixed in 3:1 (ethanol:acetic acid) for propionic-carmine staining to investigate pollen viability and stages of development. Microspores were staged under Zeiss Axioplan Universal microscope.

Analysis of variance was performed on pollen viability data using a split-plot design. Main plots consisted of a three-factor factorial design: blocks (days of inoculation); media (B5 and B5 long); and flower bud size $(2.5-2.9 \mathrm{~mm}$ and $3.0-3.5$ $\mathrm{mm})$. Subplots consisted of culture period $(0,10$, 15 , and 20 days after culture initiation). Several transformations were tried on data from propioniccarmine assay with weighted least-squares method using the inverse-variance as weight, thus yielding the best result. Means were compared using Tukey's test. 
Data on binucleate symmetrical and multinucleate pollen grains were analyzed using Kruskal-Wallis non-parametric analysis of variance. Bud sizes, culture media and days of culture were then pairwise compared using ranks (LSD test) at 0.05 significance level.

\section{RESULTS AND DISCUSSION}

\section{Developmental Stage}

Cytological analysis of soybean cultured anthers was carried out to determine the developmental stage at inoculation time and microspore segmentation throughout the culture period. Fig. 1 shows the main stages found in propionic-carmine analysis. The results obtained at inoculation time are summarized in Fig. 2. Flower buds with 2.5-
$2.9 \mathrm{~mm}$ in size presented some cells at meiosis $(4.99 \%)$. The most frequent stage was uninucleate microspore $(57.15 \%)$. Uninucleate and binucleate asymmetrical pollen grains were the most frequent stages ( $51.66 \%$ and $46.53 \%$ respectively) in flower buds with $3.0-3.5 \mathrm{~mm}$ in size.

Symmetrical mitotic division of microspores has been considered as one of the main routes in androgenetic induction (Zaki and Dickinson, 1990; Zhao et al., 1996). Symmetricity of nuclear division has been suggested as an important factor to switch the gametophytic program of the pollen grain toward the embryogenic pathway (Smýkal, 2000). The occurrence of symmetrical binucleated pollen was reported in soybean and it is one of the possible routes for callus formation (Yin et al., 1980; Kaltchuk-Santos et al., 1997).
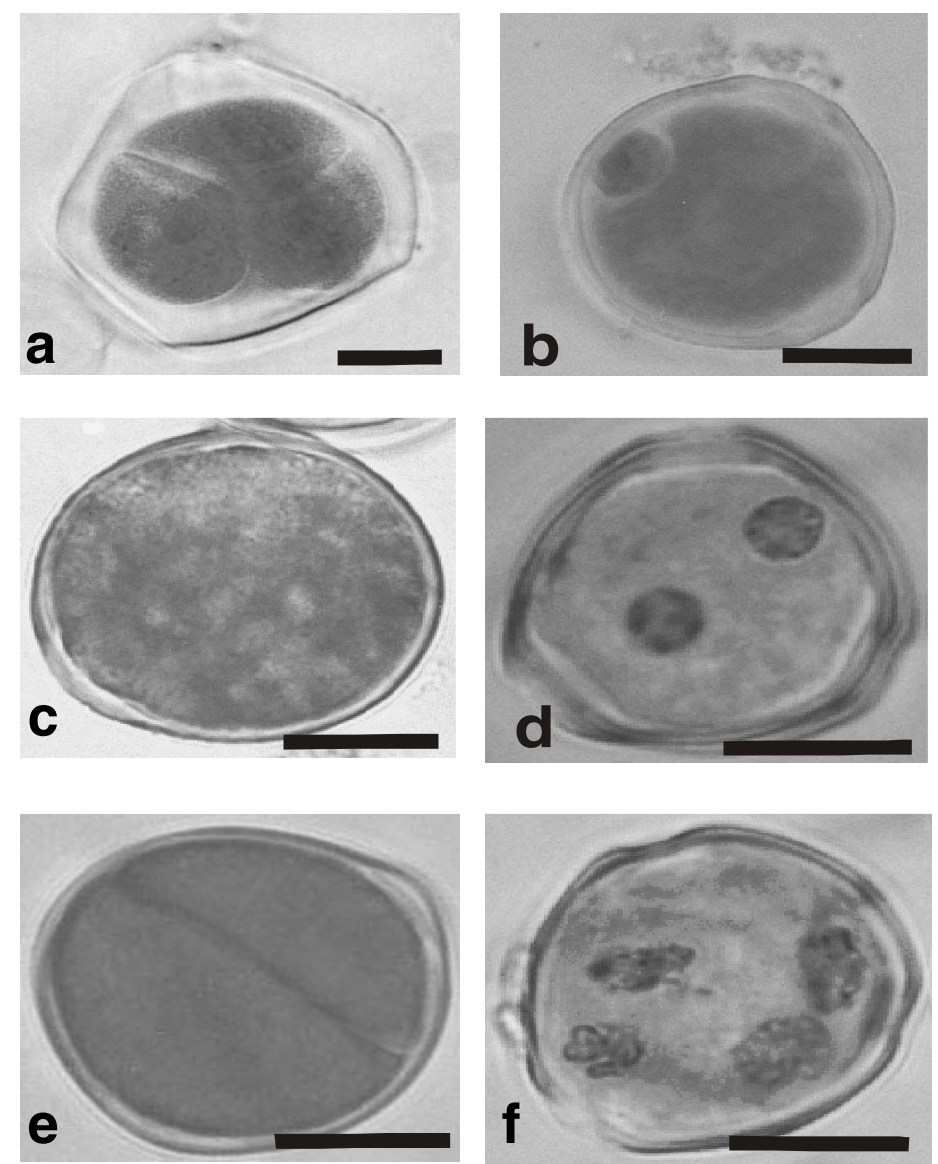

Figure 1 - Main stages found in propionic-carmine analysis. a) tetrade; b) binucleate asymmetrical pollen grain; c) binucleate asymmetrical starch filled; d) binucleate symmetrical without cell wall; e) bicellular symmetrical pollen grain; f) multinucleate. Bars $=10 \mu \mathrm{m}$. 
Cytological analysis was performed using samples of anthers on the first 20 days of culture. Considering the importance of symmetrical (Fig. 1d and 1e) and multinucleate (Fig. 1f) pollen grains for callus and embryo formation, the statistical analysis only included this information. Data are summarized in Table 1. As a general rule, the frequencies of binucleate symmetrical and multinucleate pollen grains increased during the culture period. The overall mean of binucleate symmetrical pollen was 0.019 for bud size 2.5 $2.9 \mathrm{~mm}$ and 0.034 for $3.0-3.5 \mathrm{~mm}$. For multinucleate pollen grains, the means were 0.004 for $2.5-2.9 \mathrm{~mm}$ buds and 0.007 for buds $3.0-3.5 \mathrm{~mm}$ in size. Similar frequencies were reported for cv IAS-5 in a previous study (Kaltchuk-Santos et al., 1997).

Although the results suggested a possible effect of flower size on the formation of binucleate symmetrical and multinucleate pollen grains, the statistical analysis did not show significant differences between ranks when using LSD test to compare groups. Similarly, the results indicated that media composition had no influence on the segmentation pattern. The overall means for binucleate symmetrical pollen grains were identical (0.026) on both media tested. Very similar means were obtained for multinucleate pollen grains: 0.005 for B5 media and 0.006 for B5 long media. These data indicated that the additional compounds present in B5 long media were not essential to trigger the androgenetic pathway. Therefore, the B5 medium could be used as a basal medium for soybean anther culture.

\section{Viability of Pollen Grains}

Table 2 shows the results of two pollen viability assays - propionic-carmine and FDA - during the first 20 days of culture. These methods are currently used for evaluating pollen quality, and both are correlated with pollen germinability (Heslop-Harrison et al., 1984; Trognitz, 1991). Ordinary staining procedures, as propionic carmine (Fig. 3a), usually overestimate pollen viability. FDA test (Fig. 3b) implies that the integrity of the plasmalemma of the vegetative cell is preserved. This way, FDA test provides a more effective method for assessing pollen quality (Heslop-Harrison and Heslop-Harrison, 1970). As expected, the frequencies of viable pollen grains in the present study were higher with propionic-carmine staining when compared to FDA. Until the 20th day, at least $50 \%$ of the grains remained viable. Although the data on the frequency of pollen viability were not found in soybean, $\mathrm{Hu}$ et al. (1996) reported that $80 \%$ of anthers presented live pollens 2 months after in vitro culture. These high frequencies of viable pollen grains were not a guarantee of pollen embryogenesis, since only a small portion of these grains would develop into embryos. Multinucleate pollen grains, which comprise just around of $1 \%$ of total of pollen population (Table 1), represent those with embryogenic potential. In Brassica, Zaki and Dickinson $(1990 ; 1995)$ reported that only $1.8 \%$ of microspores from cultured anthers followed an embryogenic pathway.

The differences between culture media on frequency of viable pollen grains were not statistically significant in FDA (Prob $>0.6755$ ) and propionic-carmine (Prob $>0.3605$ ) staining assays. The frequencies of viable pollen grains varied significantly between bud sizes (Prob $>0.0213$ ) on the propionic-carmine analysis. Flower buds with $3.0-3.5 \mathrm{~mm}$ in size showed lower pollen viability $($ mean $=0.748)$ when compared with those $2.5-2.9$ $\mathrm{mm}$ in size (mean=0.784). These results were probably related to the earlier microspore stage in flower buds with $2.5-2.9 \mathrm{~mm}$ in size at inoculation time (Fig. 2).

\section{Chromosome Doubling}

Results obtained in our laboratory showed that the androgenetic structures obtained were often diploid (unpublished data). Therefore, it was not clear whether these structures were formed from somatic tissue or from microspores in which spontaneous chromosome doubling occurred.

Another possible source are abnormal unreduced gametes (Collins et al., 1974).

Since metaphase last for a short time, it is usually hard to visualize it in microspores. Nevertheless, the number of metaphasic cells recorded in the present study allowed a more detailed analysis. Table 3 shows chromosome counts throughout the culture period. In addition to the microspores with normal chromosome number $(n=20$, Fig. $4 a)$, we observed microspores in higher numbers $(n=40,60$ and 80 , Fig. $4 \mathrm{~b}$ and $4 \mathrm{c}$ ). The first microspores with chromosome doubling were observed 5 days after culture initiation. 

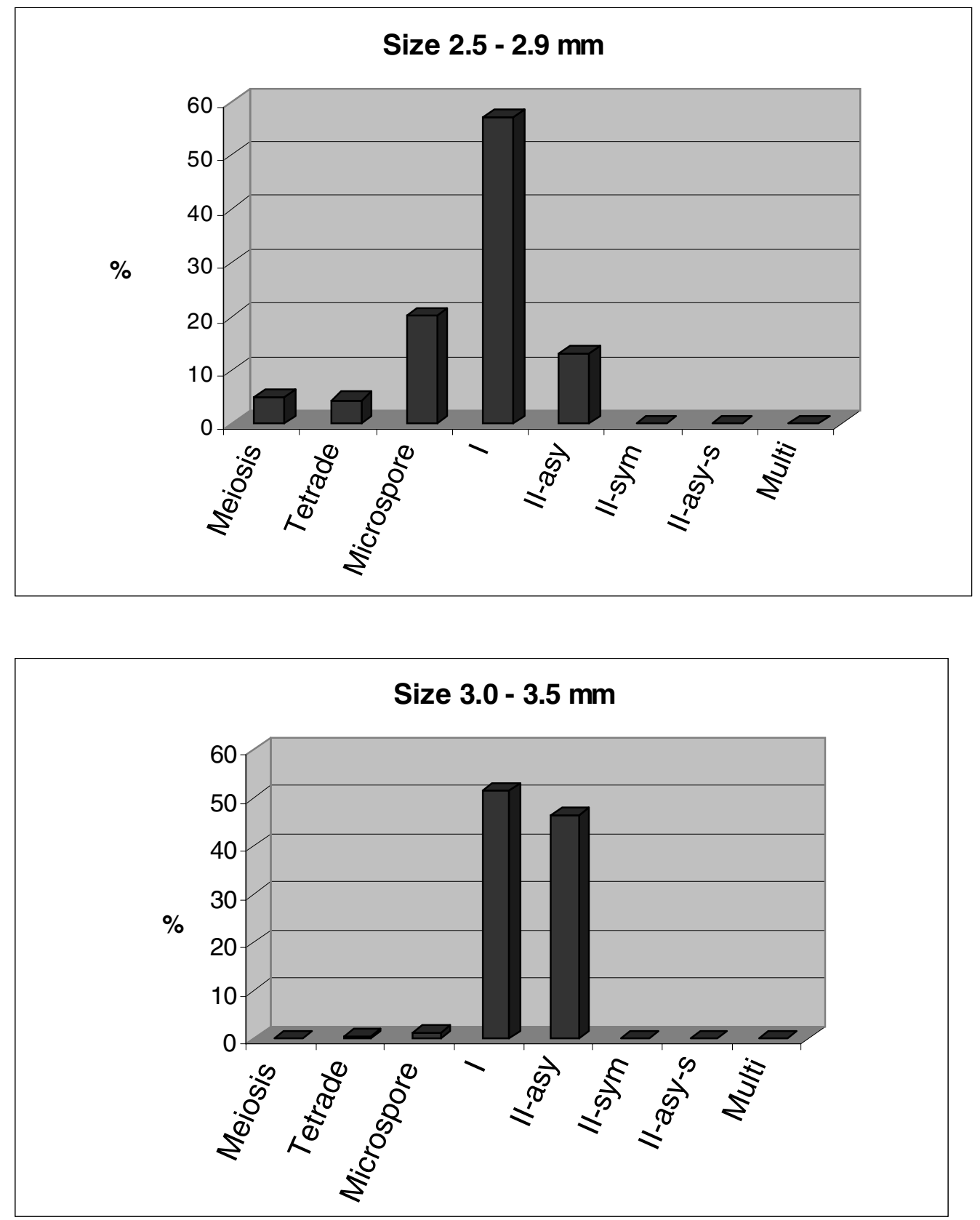

Figure 2 - Percentage of each type of pollen grain at inoculation time. I=uninucleate; IIasy=binucleate asymmetrical; II-sym=binucleate symmetrical; II asy$\mathrm{s}=$ binucleate asymmetrical starch filled; Multi=multinucleate. 
Table 1 - Frequencies of binucleate symmetrical and multinucleate pollen grains for IAS-5 soybean cultivar through the culture period.

\begin{tabular}{|c|c|c|c|c|c|}
\hline Media & $\begin{array}{l}\text { Bud size } \\
\quad(\mathbf{m m})\end{array}$ & $\begin{array}{l}\text { Days after } \\
\text { inoculation }\end{array}$ & $\begin{array}{l}\text { Number } \\
\text { of cells }\end{array}$ & $\begin{array}{c}\text { Mean for binucleate } \\
\text { symmetrical pollen } \\
\text { grains }\end{array}$ & $\begin{array}{c}\text { Mean for multinucleate } \\
\text { pollen grains }\end{array}$ \\
\hline \multirow{9}{*}{ B5 } & \multirow{4}{*}{$2.5-2.9$} & $\mathbf{0}$ & 7722 & 0.0012 & 0.0017 \\
\hline & & 5 & 4958 & 0.0058 & 0.0037 \\
\hline & & 10 & 4299 & 0.0182 & 0.0021 \\
\hline & & 15 & 3822 & 0.0359 & 0.0049 \\
\hline & \multirow{6}{*}{$3.0-3.5$} & 20 & 5546 & 0.0329 & 0.0091 \\
\hline & & $\mathbf{0}$ & 15945 & 0.0003 & 0.0007 \\
\hline & & 5 & 6830 & 0.0198 & 0.0021 \\
\hline & & 10 & 5247 & 0.0510 & 0.0062 \\
\hline & & 15 & 5591 & 0.0381 & 0.0076 \\
\hline \multirow{11}{*}{ B5 long } & & 20 & 6740 & 0.0634 & 0.0149 \\
\hline & \multirow{4}{*}{$2.5-2.9$} & $\mathbf{0}$ & 11492 & 0.0001 & 0.0001 \\
\hline & & 5 & 6163 & 0.0120 & 0.0008 \\
\hline & & 10 & 4941 & 0.0310 & 0.0037 \\
\hline & & 15 & 4971 & 0.0236 & 0.0065 \\
\hline & \multirow{6}{*}{$3.0-3.5$} & 20 & 4788 & 0.0302 & 0.0118 \\
\hline & & $\mathbf{0}$ & 15791 & 0.0004 & 0.0000 \\
\hline & & 5 & 6895 & 0.0161 & 0.0023 \\
\hline & & 10 & 7672 & 0.0305 & 0.0060 \\
\hline & & 15 & 5602 & 0.0626 & 0.0097 \\
\hline & & 20 & 6216 & 0.0593 & 0.0023 \\
\hline
\end{tabular}

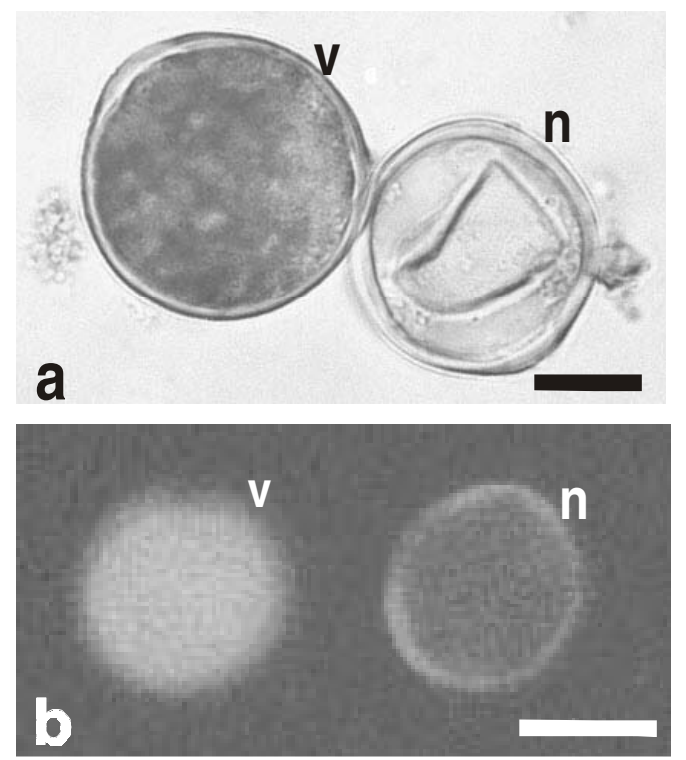

Figure 3 - Pollen viability tests, showing viable and nonviable pollen grains. a) propioniccarmine staining procedure; b) FDA fluorochromatic reaction. v=viable; $\mathrm{n}=$ nonviable. Bars $=10 \mu \mathrm{m}$ 
Table 2 - Frequency of viable pollen grains through the culture period for two staining methods.

\begin{tabular}{ccccc}
\hline Medium & Size $(\mathbf{m m})$ & $\begin{array}{c}\text { Days after } \\
\text { inoculation }\end{array}$ & Propionic-carmine & FDA \\
& & & Mean for viable pollen & Mean for viable pollen \\
\hline \multirow{3}{*}{$\mathbf{3 5}$} & $\mathbf{2 . 5}-\mathbf{2 . 9}$ & $\mathbf{1 0}$ & 0.941 & 0.506 \\
& & $\mathbf{1 5}$ & 0.785 & 0.646 \\
& & $\mathbf{2 0}$ & 0.716 & 0.587 \\
& $\mathbf{3 . 0}-\mathbf{3 . 5}$ & $\mathbf{1 0}$ & 0.737 & 0.552 \\
& & $\mathbf{1 5}$ & 0.922 & 0.542 \\
& & $\mathbf{2 0}$ & 0.714 & 0.605 \\
& $\mathbf{2 . 5}-\mathbf{2 . 9}$ & $\mathbf{1 0}$ & 0.671 & 0.564 \\
& & $\mathbf{1 5}$ & 0.642 & 0.549 \\
& & $\mathbf{2 0}$ & 0.963 & 0.504 \\
& & $\mathbf{0}$ & 0.742 & 0.616 \\
& & $\mathbf{1 0}$ & 0.726 & 0.547 \\
& $\mathbf{3 . 0}-\mathbf{3 . 5}$ & $\mathbf{1 5}$ & 0.683 & 0.537 \\
& & $\mathbf{2 0}$ & 0.945 & 0.577 \\
\end{tabular}

By day 10, most of the metaphasic microspores had their chromosome number duplicated. These data suggested that in vitro culture conditions could induce chromosome duplication. On top of that the increase in the ploidy level occurs at an early stage of culture. Similar findings were also reported by Chen et al. (1984) and Henry (1998).

Table 3 - Frequencies of microspores with chromosome doubling throughout the culture period.

\begin{tabular}{ccc}
\hline Days & Number of microspores in metaphase & Microspores with chromosome doubling \\
\hline $\mathbf{0}$ & 129 & - \\
$\mathbf{5}$ & 26 & $13(50 \%)$ \\
$\mathbf{1 0}$ & 161 & $134(83.23 \%)$ \\
$\mathbf{1 5}$ & 8 & $6(75 \%)$ \\
$\mathbf{2 0}$ & 4 & - \\
\hline
\end{tabular}

The data suggested spontaneous diploidization, which might be caused by nuclear fusion. According to Chen et al. (1984), nuclear fusion in barley usually takes place between the products of the first mitosis in symmetric or asymmetric pollen grains. Therefore, the fusion can occur between identical nuclei or between vegetative and generative nuclei in interphase. This event is favored by the lack of cellular wall and synchronous mitosis.

We observed lack of cellular wall in binucleate symmetrical and multinucleate pollen grains of soybean (Fig. 1d and 1f). Synchronous mitosis
(Fig. 4d) was also observed. In addition, the occurrence of adjacent nuclei suggests the possibility of fusion (Fig. $4 \mathrm{e}$ and $4 \mathrm{f}$ ). Similar pictures were presented by Sunderland et al. (1974) and Chen et al. (1984).

Spontaneous chromosome duplication in microspore or anther culture was reported for many species. In rice, the ploidy level of androgenetic plants varies from haploid to pentaploid (Nishi and Mitsuoka, 1969). In Datura studies have shown that $2 n, 3 n$ and $4 n$ plants were produced in addition to the regular haploid type (Sunderland et al. 1974). Wilson et al. (1978) 
reported haploid, diploid, polyploid and mixoploid callus production in barley.

Spontaneous diploidization might occur at a high frequency in some species. In Brassica, some genotypes can reach 30 to $40 \%$ of pollen- and microspore-derived embryos with increased ploidy level (XuHan et al., 1999). Martin and Widholm (1996) reported that $20 \%$ of the embryo-like structures obtained in maize anther culture were diploid.

Spontaneous doubling of chromosomes in anther culture is highly desirable, thus avoiding artificial chromosome doubling, which is time-consuming and tedious. The high frequency of spontaneous diploidization presented for IAS $5 \mathrm{cv}$. on this study suggest that chromosome doubling by colchicine treatment could be eliminated in soybean.
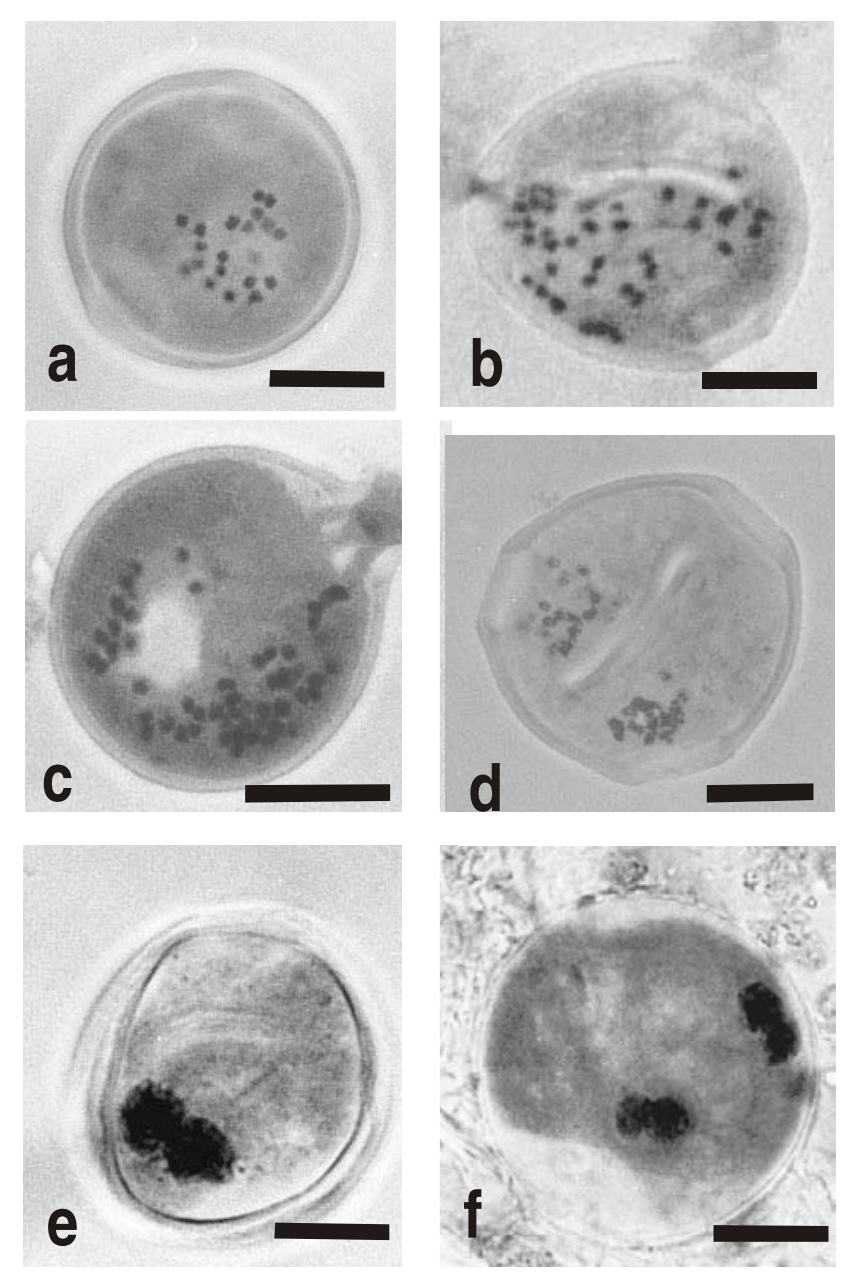

Figure 4 - Evidences for spontaneous chromosome doubling. a, b and c: metaphasic pollen grains. a) $n=20$ (normal); b) $n=40$; c) $n=60$. d) Synchronous mitosis in a pollen grain. e) and f): pollen grains with similar nuclei appearing to undergo fusion. Bars $=10 \mu \mathrm{m}$.

\section{ACKNOWLEDGEMENTS}

This study was partially supported by Conselho Nacional de Desenvolvimento Científico e Tecnológico (CNPq, Brazil), Financiadora de
Estudos e Projetos (FINEP, Brazil) and Fundação de Amparo à Pesquisa do Estado do Rio Grande do Sul (FAPERGS, Brazil). 


\section{RESUMO}

Anteras obtidas de botões florais da cultivar IAS-5 de soja foram cultivadas em dois meios de cultura basais (B5 e B5 longo). Análises citológicas das anteras cultivadas in vitro foram realizadas durante os primeiros 20 dias de cultura, a fim de avaliar a viabilidade (por testes de carmim propiônico e FDA) e o estágio de desenvolvimento dos grãos de pólen. As frequiências de grãos de pólen viáveis variaram significativamente entre os tamanhos de botões florais na análise com carmim propiônico. $\mathrm{O}$ meio de cultura basal e o tamanho do botão floral não têm um claro efeito nas frequiências de pólens binucleados simétricos e multinucleados. Contagens cromossômicas de micrósporos metafásicos ao longo do período de cultura mostraram nível de ploidia superior ao normal $(\mathrm{n}=20)$.

\section{REFERENCES}

Atanassov, A.; Zagorska, N.; Boyadjiev, P. and Djilianov, D. (1995), In vitro production of haploid plants. World Journal of Microbiology and Biotechnology, 11, 400-408.

Chen, C. C.; Kasha, K. J. and Marsolais, A. (1984), Segmentation patterns and mechanisms of genome multiplication in cultured microspores of barley. Canadian Journal of Genetics and Cytology, 26, 475-483.

Collins, G. B.; Dunwell, J. M. and Sunderland, N. (1974), Irregular microspore formation in Datura innoxia and its relevance to anther culture. Protoplasma, 72, 365-378.

Gamborg, O. L.; Miller, R. A. and Ojima, K. (1968), Nutrient requirements of suspension cultures of soybean root cells. Experimental Cell Research, 50, 151-158.

Henry, Y. (1998), Origin of Microspore-Derived Dihaploid and Polyhaploid In Vitro Plants. Plant Tissue Culture and Biotechnology, 4, 3-4.

Heslop-Harrison, J. and Heslop-Harrison, Y. (1970), Evaluation of pollen viability by enzymatically induced fluorescence; intracellular hydrolysis of fluorescein diacetate. Stain Technology, 45 : (3), 115-120.

Heslop-Harrison, J.; Heslop-Harrison, Y. and Shivanna, K. R. (1984), The evaluation of pollen quality, and a further appraisal of the fluorochromatic (FCR) test procedure. Theoretical and Applied Genetics, 67, 367-375.

Hu, C.; Yin, G. and Bodanese-Zanettini, M. H. (1996), Haploid of Soybean. In: Mohanjain, S.; Sopory, S. K. and Veilleux, R. E. (Eds.). In vitro Haploid Production in Higher Plants. London : Kluwer Academic Publishers. v. 3. pp. 377-395.
Ivers, D. R.; Palmer, R. R. and Fehr, W. R. (1974), Anther culture in soybean. Crop Science, 14, 891-893.

Jian, Y.; Lio, D.; Luo, X. and Zhao, G. (1986), Studies on induction of pollen plants in Glycine max (L.) Merr. Chiang-sunung-yeh-hseuh-pao, China: Chiangsu shengning yeh K'o hseuh yuan, J. Agri. Sci. Nanjing, 2 : (suppl), 26-30.

Kaltchuk-Santos, E.; Zanettini, M. H. B. and Mundstock, E. (1993), Pollen dimorphism in soybean. Protoplasma, 174, 74-78

Kaltchuk-Santos, E.; Mariath, J. E.; Mundstock, E.; Hu, C. and Bodanese-Zanettini, M. H. (1997), Cytological analysis of early microspore divisions and embryo formation in cultured soybean anthers. Plant Cell, Tissue and Organ Culture, 49, 107-115.

Lauxen, M. S.; Kaltchuk-Santos, E.; Hu, C. Y.; Callegari-Jacques, S. M. and Bodanese-Zanettini, M. H. (2003), Association between floral bud size and developmental stage in soybean microspores: implications for anther culture. Brazilian Archives of Biology and Technology, 46 : (4), 515-520.

Maheshwari, S. C.; Rashid, A. and Tyagi, A. K. (1982), Haploids from pollen grain - Retrospect and Prospect. American Journal of Botany, 69 : (5), 865-879.

Martin, B. and Widholm, J. M. (1996), Ploidy of small individual embryo-like structures from maize anther cultures treated with chromosome doubling agents and calli derived from them. Plant Cell Reports, 15, 781-785.

Nishi, T. and Mitsuoka, S. (1969), Occurrence of various ploidy plants from anther and ovary culture of rice plant. Japan Journal of Genetics, 44 : (6), 341-346.

Reynolds, T. L. (1997), Pollen embryogenesis. Plant Molecular Biology, 33, 1-10.

Smýkal, P. (2000), Pollen embryogenesis - the stress mediated switch from gametophytic to sporophytic development - current status and future prospects. Biologia Plantarum, 43 : (4), 481-489.

Sunderland, N.; Collins, G. B. and Dunwell, J. M. (1974), The role of nuclear fusion in pollen embryogenesis of Datura innoxia Mill. Planta, 117, 227-241.

Tang, W. T.; Ling, T. S. and Chang, C. S. (1973), Effects of kinetin and auxin on callus formation in anther tissue cultures of soya bean. J. Agri. Asso. China (Chung-hua Nung-hsueh Hui Pao), 83, 1-7.

Trognitz, B. R. (1991), Comparison of different pollen viability assays to evaluate pollen fertility of potato dihaploids. Euphytica, 56, 143-148.

Wilson, H. M.; Mix, G. and Foroughi-Wehr, B. (1978), Early microspore division and subsequent formation of microspore calluses at high frequency in anthers of Hordeum vulgare L. Journal of Experimental Botany, 29 : (108), 227-238. 
Xuhan, X.; Jing, H. C.; Cheng, X. F.; Iwanowska, A.; Kieft, H.; Bergervoet, J. H. W.; Groot, S. P. C.; Bino, R. J. and Van Lammeren, A. A. M. (1999), Polyploidization in embryogenic microspore cultures of Brassica napus L. cv. Topas enables the generation of doubled haploid clones by somatic embriogenesis. Protoplasma, 208, 240-247.

Yeung, E. C. and Sussex, I. M. (1979), Embryogeny of Phaseolus coccineus: The suspensor and the growth of the embryo-proper in vitro. $Z$. Planzenphysiol, 91, 423-433.

Yin, G. C.; Li, X. Z.; Xu, Z.; Chen, L.; Zhu, Z. Y. and Bi, F. Y. (1980), Anther culture of Glycine max. Kexue Tongboa, 25, 11, 976.

Yin, G. C.; Zhu, Z. Y.; Xu Z.; Chen, L.; Li, X. Z. and Bi, F.Y. (1982), Studies on induction of pollen plant and their androgenesis in Glycine max (L.) Merr. Soybean Science, 1 : (1), 69-76.

Zaki, M. A. M. and Dickinson, H. G. (1990), Structural changes during the first divisions of embryos resulting from anther and free microspore culture in Brassica napus. Protoplasma, 156 : (3), 149-162.
Zaki, M. A. M. and Dickinson, H. G. (1995), Modification of cell development in vitro: The effect of colchicine on anther and isolated microspore culture in Brassica napus. Plant Cell, Tissue and Organ Culture, 40, 255-270.

Zhao, J. P.; Simmonds, D. H. and Newcomb, W. (1996), Induction of embryogenesis with colchicine instead of heat in microspores of Brassica napus L. cv. Topas. Planta, 198, 433-439.

Zhuang, X. J.; Hu, C. Y.; Chen, Y. and Yin, G. C. (1991), Embryoids from soybean anther culture. In Vitro Cellular and Developmental Biology, 27 : (3), Part II, 145A (Abstr. \# 432).

Received: February 03, 2003; Revised: July 28, 2003; Accepted: February 12, 2004. 